BULLETIN Bulletin hispanique

HISPANIQUE Université Michel de Montaigne Bordeaux

116-2 | 2014

Référentialité/autoréférentialité dans le roman

espagnol contemporain : bilan et perspectives

\title{
Manuel Alvar Ezquerra, Las nomenclaturas del español. Siglos XV-XIX
}

Liceus, Madrid, 2013

\section{Ángeles García Aranda}

\section{OpenEdition \\ Journals}

\section{Edición electrónica}

URL: http://journals.openedition.org/bulletinhispanique/3671

DOI: 10.4000/bulletinhispanique.3671

ISBN: 979-10-300-0156-3

ISSN: 1775-3821

Editor

Presses universitaires de Bordeaux

\section{Edición impresa}

Fecha de publicación: 1 diciembre 2014

Paginación: 919-922

ISBN: 978-2-86781-963-6

ISSN: 0007-4640

Referencia electrónica

Ángeles García Aranda, « Manuel Alvar Ezquerra, Las nomenclaturas del español. Siglos XV-XIX», Bulletin hispanique [En línea], 116-2 | 2014, Publicado el 01 diciembre 2014, consultado el 23 septiembre 2020. URL : http://journals.openedition.org/bulletinhispanique/3671 ; DOI : https://doi.org/10.4000/ bulletinhispanique.3671

Este documento fue generado automáticamente el 23 septiembre 2020.

Tous droits réservés 


\section{Manuel Alvar Ezquerra, Las nomenclaturas del español. Siglos XV- XIX}

Liceus, Madrid, 2013

Ángeles García Aranda

\section{REFERENCIA}

Manuel Alvar Ezquerra, Las nomenclaturas del español. Siglos XV-XIX, Madrid, Liceus, 2013. - ISBN 978-84-9714-042-3

1 Las nomenclaturas del español de Manuel Alvar Ezquerra constituye uno de los capítulos de la historia de los diccionarios del español que están todavía por hacer. En sus páginas se revisan la estructura, el contenido, las fuentes y las principales características de más de ciento cincuenta repertorios redactados a lo largo de más de cuatro siglos, lo que ha sido posible, según explica su autor, gracias a la labor llevada a cabo durante muchos años en el seno tanto del Nuevo Tesoro Lexicográfico del español (junto a Lidio Nieto Jiménez) como de su actual proyecto de investigación, la Biblioteca Virtual de la Filología Española (http://biblioteca.ucm.es/nebrija/).

2 Los primeros repertorios temáticos de que tenemos noticia fueron compuestos en la Edad Media: el desconocimiento del griego y del latín obligaron a la elaboración de repertorios bilingües ordenados por materias que solían empezar por la descripción de Dios y continuar con el hombre, el reino animal, el reino vegetal y, en ocasiones, finalizar con el léxico de la muerte y la sepultura; distribución que heredan, en mayor o menor medida, casi todas las lenguas modernas. En los siglos XVI y XVII, momento en el que se conjugan varias circunstancias que condicionan nuestras relaciones con el exterior (España se abre a Europa, el latín es desconocido por buena parte de la población $\mathrm{y}$ es imposible su utilización como lingua franca, las colonias extrapeninsulares crecen y con ellas el comercio y el intercambio, las tropas han de 
mantener la paz en los territorios europeos conquistados y sus soldados necesitan aprender nuevas lenguas...), los objetivos de las nomenclaturas se modifican y de ser un instrumento de acercamiento a una lengua muerta pasan a reflejar las necesidades sociales, económicas y políticas de una sociedad que ha cambiado, convirtiéndose así en materiales útiles y muy prácticos para desenvolverse en situaciones cotidianas, pues, como señala Manuel Alvar Ezquerra (2013: 19-20), se desarrollaron «con una finalidad práctica inmediata, y de eminente carácter didáctico, en las que se hace una clasificación de la realidad extralingüística, esto es, de las ideas que tenemos de las cosas, de manera que el mundo queda parcelado, repartiéndose el vocabulario a lo largo de esas divisiones». En la tradición hispana este tipo de ordenación fue inaugurada por Antonio de Nebrija, quien al final de la edición burgalesa de las Introductiones latinae de 1493 incluyó un «Lexicon parvum seu vocabularium» destinado a facilitar la enseñanza del latín. A partir de este momento nuestra lengua aparece en otras muchas nomenclaturas, tanto hispanolatinas como plurilingües con otras lenguas modernas.

De todas ellas, así como de las del español con lenguas amerindias o con las lenguas de Filipinas, se ocupa Manuel Alvar Ezquerra en este volumen. Para su descripción ha seguido un criterio cronológico: el primer capítulo se centra en los siglos XV y XVI o la llegada de las nomenclaturas del español, el segundo capítulo trata sobre el desarrollo de las nomenclaturas del español durante el siglo XVII, el tercero sobre las nomenclaturas compuestas en el siglo XVIII y el cuarto sobre la proliferación de nomenclaturas en el siglo XIX. Hay lugar, en cada uno de estos apartados, para el análisis de textos latinos, franceses, ingleses, italianos, portugueses, alemanes, flamencos, vascos, catalanes, árabes y hasta uno con el cakchiquel, otros con el tagalo, otro con el totonaca, otro con el pangasinán y otro con el yucateco; para la presentación de nomenclaturas monolingües, bilingües y plurilingües; para el examen de extensos repertorios publicados individualmente y de breves listas de palabras que acompañan a gramáticas, diálogos o diccionarios alfabéticos; para la exposición de nomenclaturas compuestas por autores como Antonio de Nebrija, César Oudin, Lorenzo Franciosini, Francisco Sobrino, John Stevens, Esteban de Rosterre, Manuel Núñes de Taboada o Ramón Joaquín Domínguez, por autores poco conocidos o anónimos (Miguel de Saura, Miguel Navarro, José Faustino Perles y Campos, la nomenclatura anónima de Bayona, el manuscrito 18453 de la BNE, Pantaléon de Guzmán, Abdón Senén Guilla Rubí, Ernesto Joseph Eder, Nicolás Vellón, Pedro Beltrán de Santa Rosa María, Charles Wiseman, Josef de Frutos, James Boardman, José R. Losáñez, Agustín Caze) y por diferentes editoriales... en suma un completo recorrido por la mal denominada Lexicografía menor.

4 Ahora bien, el volumen Las nomenclaturas del español no es solo una lista de los repertorios temáticos del español compuestos hasta el siglo XIX, sino que profundiza en las características de cada uno de esos repertorios, en las dificultades que entraña compendiar el léxico de una lengua en unos cuantos ámbitos designativos (porque ¿dónde empieza un capítulo y termina otro?, ¿dónde están los límites de cada ámbito designativo?, ¿dónde colocar un término -sobre todo los polisémicos- que tiene cabida en más de un epígrafe?, ¿acaso el autor no ordena el léxico a partir de criterios subjetivos que no tienen por qué coincidir con los del lector y que, por tanto, dificultan considerablemente la búsqueda del léxico?), y en su contenido léxico (da cuenta del número de epígrafes y de artículos lexicográficos de cada nomenclatura), a fin de establecer el lugar que debe ocupar cada texto en la historia de nuestros diccionarios. 
5 Así, por ejemplo, se demuestra que el «Lexicon parvum seu vocabularium» de Antonio de Nebrija «no es una obra perfecta» y contiene «todavía algún resabio medieval» (página 27); se enfrenta, al presentar el Quinque linguarum de Francesco Garrone, al «enorme enredo [bibliográfico] que se produce con los primeros vocabularios de carácter temático» (página 33); evidencia que The Spanish Scholle-master de William Stepney «contiene 48 primeras documentaciones en la historia de nuestra lexicografía [...] lo que lleva a afirmar que el pequeño diccionario de Stepney, pese a ser una nomenclatura en la que sería esperable un léxico cotidiano, resulta más importante de lo que cabría sospechar para la historia de nuestro léxico y de nuestros diccionarios» (páginas 60-61), o que los «epígrafes, estructura y distribución, así como el contenido» de la Nomenclatura de Lorenzo de Robles, pese a no suponer una novedad dentro de la tradición lexicográfica, «demuestran que están concebidos para una utilidad práctica, la enseñanza de lo más inmediato a quienes se movían entre los dos países» (página 126), o que el Lexicon Tetraglotton de James Howell recoge léxico específico (términos químicos, terminología del arte de la guerra, de la fortificación, de las armas, de la artillería, de la heráldica, de la arquitectura, de las enfermedades, de la navegación, de las órdenes religiosas...) lo que resulta «un elemento caracterizador de la nomenclatura» (página 203), o el «carácter particular» de la Janua linguarum de Joannes Amos Comerius (página 209), o la singularidad de los repertorios de Matthias Kramer, o el interés, "porque muestra cómo se efectúa la transmisión de los repertorios no alfabéticos de dos lenguas que no andaban muy sobradas de ellos», de la nomenclatura de Ernesto J. Eder (página 276), o la "particularidad de poner, además de las formas españolas y las francesas, una tercera columna con la pronunciación figurada en francés» (página 311) que introdujo Antoine Galmace, o la riqueza léxica, «pues tanto en español como en italiano son numerosos los artículos en que se nos muestran varios sinónimos» (página 343) del Diccionario familiar de Esteban de Rosterre, o que del Diccionario manual de Josef de Frutos «es un tardío representante de las colecciones temáticas plurilingües, con la característica de que el léxico de muchos de sus apartados se ordena alfabéticamente, lo cual no parece el mejor método para recordar el vocabulario que se va aprendiendo» (página 394), o la introducción de epígrafes novedosos en la tradición de las nomenclaturas de Juan José Romero, quien incluye «Voces de mando en el ejército» o «Graduaciones en el ejército» (página 527).

6 Del mismo modo, justifica la escasa originalidad de Lorenzo Franciosini, quien «suprimió el francés de la nomenclatura de César Oudin y puso los equivalentes italianos» (página 164) o la de Jerónimo de Tejeda, cuyas «cinco páginas más parecen un relleno para completar hojas en blanco que cualquier otra cosa» (página 175), o la de José Faustino Perles y Campos, o la de Mauricio Bouynot, «quien se limitó a copiar la nomenclatura de Chantreau» (págin 439), y la riqueza, por el contrario, de las nomenclaturas de Jean Perger, de Pantaleón de Guzmán, de François Antoine Pomey, de José Patricio Moraleja, de David de Torres, de Joseph Broch, de Francisco Cañes, de Josef de Frutos, de William Casey, de Manuel Aínsa Royo o de Eugenio de Ochoa, por poner solo algunos ejemplos.

7 Los análisis y las descripciones pormenorizadas de cada una de las nomenclaturas permite a Manuel Alvar Ezquerra, por un lado, descubrir las relaciones filogenéticas entre los repertorios (es así como descubrimos que Lorenzo de Robles inspiró a César Oudin y a seguidores como Lorenzo Franciosini, Marcos Fernández, Fransico Sobrino, Félix Antonio de Alvarado, John Stevens o Mattia Chirchimair; que Nicolás Chantreau 
fue seguido por Pierre Beaume, por Luis de Astigarra y Ugarte, por Pablo Dupuy, por Antonio Bergnes de las Casas, por Z. Sauzeau, por José R. Losáñez, por Francisco Jáuregui de San Juan, por J. Delgado Campos; que Timoteo Cemboráin sigue a William Casey, quien, a su vez, copia a José de Urcullu; que Francisco Anglada es continuador de José Llausás y Mata; que The Boke of Englysshe and Spanisshe presenta notables coincidencias con el Quinque linguarum de Francesco Garrone; que el Tesoro de la lengua castellana abreviado, manuscrito 18157 de la BNE, toma como fuente la Plaza universal de Cristóbal Suárez de Figueroa; que la nomenclatura de Sebastián Roca y María se basa en las de Perger y Sobrino, e inspiró la de Joseph Broch; que Raymundo del Pueyo y Felipe Fernández copiaron a Hipólito San José Giral Delpino, quien había consultado la de John Stevens; o que el repertorio de Juan Ángel Zumarán está detrás del de Ernesto Joseph Eder), y, por otro lado, conocer con detalle su nacimiento y su evolución (se aprecia, por ejemplo, que el paso del tiempo simplificó los materiales; que se redujeron los epígrafes sobre Dios, los pecados capitales, los diez mandamientos, el padre nuestro, el ave maría o el vocabulario sobre el alma, y que, en cambio, se introdujeron, sobre todo a partir del siglo XIX, epígrafes con léxico comercial, de los caminos de hierro o de barcos a vapor; o que empezaron a formar parte de métodos de enseñanza de lenguas más amplios, como el ollendorff, o a acompañar a guías de conversación y manuales de viajeros).

8 La gran cantidad de nombres y obras que se encuentran citadas en este libro ha exigido la consulta de numerosas fuentes bibliográficas -tanto primarias como secundarias-, y de todas ellas se da cuenta en notas a pie de página (en donde aparecen referencias completas, bibliotecas de origen, signaturas de los ejemplares y, si están digitalizadas, el enlace en que puede realizarse la consulta), en la bibliografía final y en un útil índice onomástico que cierra el volumen (elaborado por Antón Alvar Nuño).

9 En definitiva, Las nomenclaturas del español es una valiosa contribución, pese a todo lo que se ha escrito sobre diccionarios, a la lexicografía del español. La calidad, el rigor y el trabajo bien hecho de estas páginas estarán presentes, con toda seguridad, en la futura historia de los diccionarios prometida por Manuel Alvar Ezquerra en su prólogo.

\section{AUTORES}

\section{ÁNGELES GARCÍA ARANDA}

Universidad Complutense de Madrid 